\title{
Linear Programming Based Hourly Peak Load Shaving Method at Home Area
}

\author{
Jae Yong Lee*, Seong Gon Choi* \\ *College of Electrical \& Computer Engineering, Chungbuk National University, South Korea \\ jyleebnl@cbnu.ac.kr, sgchoi@cbnu.ac.kr
}

\begin{abstract}
We propose a method about power consumption scheduling for shaving peak load at home area using linear programming technique. Problems caused by peak load such as blackout and rolling blackout has occurred recently in the world because hourly peak load consumption is increased rapidly in the same time. So to solve these problems is using ESS. Especially, the most effective method is to utilize ESS and V2G. Electricity of the battery of parked PHEV at home area transmits through V2G to the ESS. The stored electricity in the ESS is optimized by using linear programming. This optimization reduces the hourly peak load consumption.
\end{abstract}

Keywords - V2G, ESS, Optimization, Linear Programming, Peak load, Smart Grid, Blackout

\section{INTRODUCTION}

The power consumption is increasing rapidly worldwide. In Korea, power consumption is increasing annually. It used $32,734 \mathrm{GWh}$ of electricity in 1980 , but as the usage continually increased it showed $395,475 \mathrm{GWh}$ in $2009,434,160 \mathrm{GWh}$ in 2010, 455,070GWh in 2011, and 466,593GWh in 2012 and it is on the rise [1]. The problems caused by peak load causes blackout and rolling blackout. On September 11, 2011 rolling blackout occurred in Korea. Just rolling blackout caused financial losses nationally. If blackout occurs, financial losses expect to be huge.

TABLE 1. Electricity USAGe IN Korea [1]

(Unit: GWh, \%)

\begin{tabular}{|c|c|c|c|c|c|}
\hline Part & $\mathbf{1 9 8 0}$ & $\mathbf{2 0 0 9}$ & $\mathbf{2 0 1 0}$ & $\mathbf{2 0 1 1}$ & $\mathbf{2 0 1 2}$ \\
\hline Home & 5,317 & 57,596 & 61,194 & 61,564 & 63,536 \\
\hline Growth & 6.8 & 2.4 & 6.3 & 0.6 & 3.2 \\
\hline
\end{tabular}

The smart grid is mentioned as a solution of this problem. Accordingly, the smart grid related study is made actively. Smart grid is an advanced electric technology that will improve the efficiency of electric utilization and transmission and solve the existing electric infrastructure problems. To solve the problems caused by peak load, it can be solved in two methods.
The first method is to build more power plants. However, the available natural resources on the earth are finite, so they cannot be a fundamental solution. The air pollution caused by power plants emitting fumes could also cause serious environmental problems. In addition, the construction of new power plants will be a huge capital investment. So this method cannot be a solution for power consumption problems caused by peak load.

The second method is using smart grid technology to solve the problems caused by peak load. Many techniques exist to solve the problems. The most effective method is to utilize ESS (Energy Storage System) and V2G (Vehicle to Grid). The ESS is a device that stores electricity when the demand is low and it provides stored electricity when the demand is high. This improves energy efficiency and stabilizes operations of the electricity grid. The V2G describes a system in which EV (Electric Vehicle) and PHEV (Plug-in Hybrid Electric Vehicle), communicate with the grid to sell demand response services by either transmitting electricity into the grid or by throttling their charging rate [7].

As mentioned above, if we use the ESS and V2G technologies appropriately, the problems caused by peak load can be solved. However, using the energy without any plan, even though there's enough energy, we will face the problem which has no solution to prevent the rolling blackout/blackout. To solve this problem, we have to think about the most suitable method how to use that energy.

In this paper, we propose power consumption scheduling for shaving peak load at home area using a linear programming technique. Electricity of the battery of parked PHEV at home area transmits through V2G to the ESS. The stored electricity in the ESS is optimized by using linear programming.

This paper is organised as follows. In section 2, we describe the related work. Section 3, we describe the proposed method that power consumption scheduling using linear programming technique. In section 4, we analyze the performance concerning proposed method. Finally, we conclude in section 5 .

\section{RELATED WORK}

\section{A. Energy Storage System (ESS)}

An ESS is a machine that stores electricity when the demand is low and supplies stored electricity when the 
demand is high. This improves stabilizes operations and energy efficiency of the electricity grid. In smart grid, where energy efficiency and reliable power supplies are important, an ESS is an essential machine, and the demand for these devices is increasing.

ESS applications are classified according to the energy capacity, power, usage time, and etc.

TABLE 2. ESS APPLICATIONS

\begin{tabular}{|c|c|c|c|c|}
\hline & \multicolumn{2}{|c|}{ Energy Storage } & \multicolumn{2}{c|}{ Energy Storage } \\
\hline & Peak Shifting & $\begin{array}{c}\text { Load } \\
\text { Leveling }\end{array}$ & $\begin{array}{c}\text { Community } \\
\text { ESS }\end{array}$ & $\begin{array}{c}\text { Residential } \\
\text { ESS }\end{array}$ \\
\hline Power & $\mathrm{MW}+$ & $\mathrm{MW}++$ & $10 \sim 25 \mathrm{~kW}$ & $3 \sim 10 \mathrm{~kW}$ \\
\hline $\begin{array}{c}\text { Discharge } \\
\text { time }\end{array}$ & $1 \sim 2 \mathrm{hrs}$ & $4 \sim 7 \mathrm{hrs}$ & $1 \sim 3 \mathrm{hrs}$ & $1 \sim 3 \mathrm{hrs}$ \\
\hline
\end{tabular}

\section{B. Vehicle to Grid (V2G)}

V2G concept is that electric vehicles supply power to the grid while parked. Battery electric vehicles can charge during low times and discharge when electricity is needed.

Each electric vehicle must have three required elements : one of three is a connection to the grid for electrical energy flow, other one is logical or control connection necessary for communication with the grid operator, and the last is controls and metering on-board the vehicle. These elements vary somewhat with the business model [9].

\section{Electric Vehicle}

Electric vehicles are classified that only motor operated EV, engine and motor cooperated HEV, and PHEV. Generally, $\mathrm{HEV}$ is an early model of electricity vehicle on the existing internal combustion engine combined with electric motor. So HEV emits exhaust gas less than general vehicle. PHEV is similar to HEV, but PHEV is possible to external charge. PHEV is designed with relatively large capacity battery packs. Finally, EV is operated only motor, so exhaust gas is nothing and also vehicle noise is nothing [3].

\section{III.PROPOSED METHOD}

\section{A. PHEV}

This paper is selecting PHEV among electric vehicles, because PHEV can charge through the plug like general appliance. So the battery of PHEV can charge from grid, and can discharge to grid. So users can make a new business model.

PHEV is designed with some large capacity battery packs. And it operates in charge-depleting mode or charge-sustaining mode. Charge-depleting mode is that PHEV is operated using the electricity of charged battery. Charge-sustaining mode is that battery state of PHEV reached SOC, then PHEV is operated hybrid driving mode [8].

\section{B. System Description}

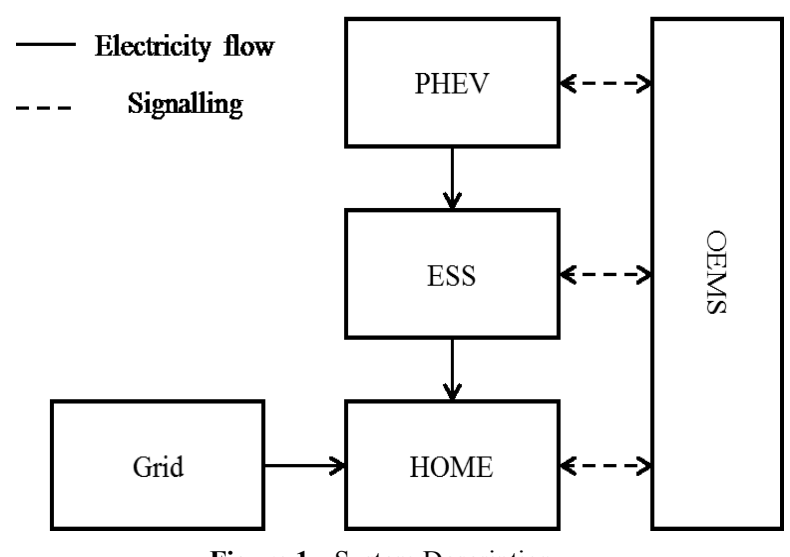

Figure 1. System Description

Fig. 1 depicts the overall structure of our proposed system. System components grid, home, ESS, PHEV, and OEMS (Optimized Energy Management System). As shown in the Fig. 1, the key component is the OEMS in the proposed system. It connects with home, ESS, and PHEV to collect the states such as power consumption usage, user consumption pattern, and battery state. PHEV is similar to HEV, but PHEV is possible to external charge. The OEMS connects with home, ESS, and PHEV not only to collect electricity but also to determine the optimization values. Grid is responsible for electricity generation and transmission. The ESS stores electricity when the demand is low and provides stored electricity. PHEV is individual plug-in hybrid electric vehicle.

This paper assumed that battery of individual PHEV is always charged full. ESS is selected residential ESS that capacity is $3 \mathrm{kWh}$.

OEMS is responsible for optimization. Optimized result is used hourly peak load shaving.

\section{Power Consumption Scheduling Optimization}

The power consumption scheduling mechanism can be described as linear programming optimization problem which aims to shave the hourly peak load, as shown below

$\min P L$

$$
\begin{array}{ll}
\text { s.t. } & \sum_{a \in \mathrm{A}} x_{a, h} \leq P L, \forall h \in \mathrm{H}, \\
& 1^{T} \mathrm{x}_{a}=l_{a}, \forall a \in \mathrm{A}, \\
& x_{a, h} \geq 0,
\end{array}
$$

where $1=[1,1,1, \ldots 1]^{T}$. We represent $a$ as individual appliance in a set of appliances, A . $\mathbf{x}_{a}=\left[x_{a, 1}, x_{a, 2}, \ldots\right.$, $\left.x_{a, 24}\right]^{T} . a$ is the schedule plan for appliance, and $x_{a, h}$ is the scheduling variable which represents the power consumption of individual appliance $a$ in the particular hour $h \in \mathrm{H}, \mathrm{H}=$ $[1,2, \ldots, 24]$ of the one day. The $P L$ defines as the hourly peak load. The cost function of the above optimization problem is to shave the hourly load subject to the constraints. The hourly load should be larger than or equal to the sum of the scheduled power for all individual appliances in that time. 
For each appliance, the total daily supplies have to meet the requirement $l_{a}$. The power consumption $x_{a, h}$ is must be positive or zero value [4].

This formulation is optimized using electricity stored in ESS, as shown below

$\min P L$

$$
\begin{array}{ll}
\text { s.t. } & \sum_{a \in \mathrm{A}} x_{a, h}-\sum_{e s s} x_{e s s, h} \leq P L, \forall h \in \mathrm{H}, \\
& 1^{T} \mathrm{x}_{a}=l_{a}, \forall a \in \mathrm{A}, \\
& x_{a, h} \geq 0, \\
& \sum_{e s s} x_{e s s, h}=3 k W h, x_{e s s, h} \geq 0,
\end{array}
$$

where $x_{e s s, h}$ is the scheduling variable which represents the stored electricity of residential ESS in the particular hour $h \in \mathrm{H}, \mathrm{H}=[1,2, \ldots, 24]$ of the one day.

\section{IV.Performance Analysis}

We analyze the performance concerning proposed method. During the summer, power consumption patterns are investigated form the household. Investigated target is general individual appliance such as TV, air conditioning, electric fan, fluorescent lamp, refrigerators, computer, monitor, washing machine, electric cooker, and hair dryer. Generally refrigerator is consumed $50-60 \mathrm{Wh}$ and it always is the fixed consumption pattern. Other appliance power consumptions are that TV $100 \mathrm{Wh}$, air conditioning $1000-1800 \mathrm{Wh}$, electric fan $30 \sim 50 \mathrm{Wh}$, fluorescent lamp $40 \mathrm{Wh}$, computer $120 \mathrm{Wh}$, monitor $40 \mathrm{Wh}$, washing machine $500 \mathrm{Wh}$, hair dryer $500 \mathrm{Wh}$, and electric cooker $1000 \mathrm{Wh}$.

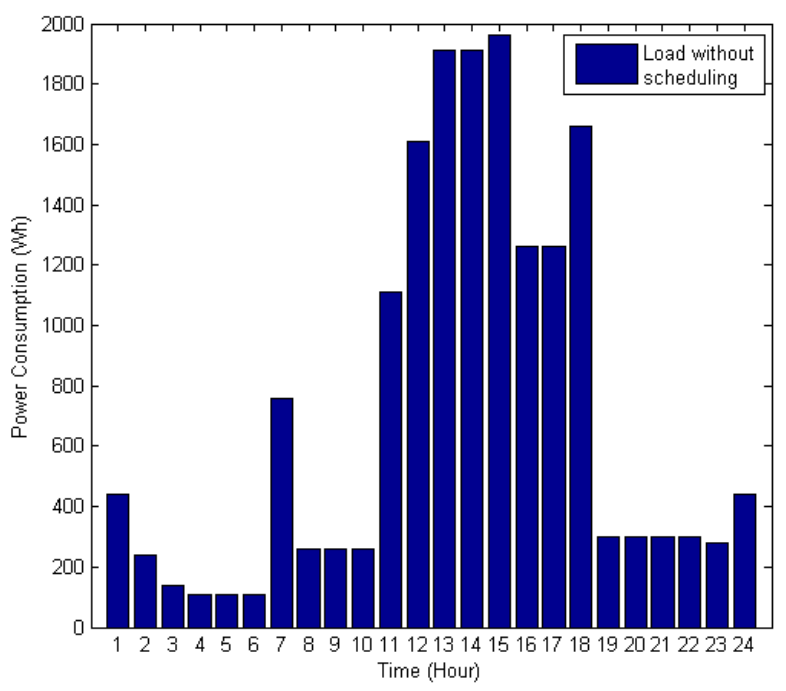

Figure 2. Hourly power consumption without scheduling

Investigated result describes Fig. 2. PM 12:00 - PM 3:00, and PM 6:00 occupied most of the power consumption. Because of high temperature, many people use air conditioning at that time. So, power consumption is increasing dramatically. At the PM 6:00, people return home from work. They consumed power, so power consumption is increasing instantly.

The system simulation has been carried out using Matlab to implement the proposed method. Fig. 2 depicts investigated value optimized through proposed method. The residential ESS was used to optimize. Fig. 3 depicts to compare the optimized power consumption with the unoptimized power consumption. Before optimizing, the hourly peak load is $1960 \mathrm{Wh}$, and after optimizing, it is $1225 \mathrm{Wh}$. As a result, hourly peak-load is reduced $735 \mathrm{Wh}$. The efficiency of the hourly peak-load is about $38 \%$.

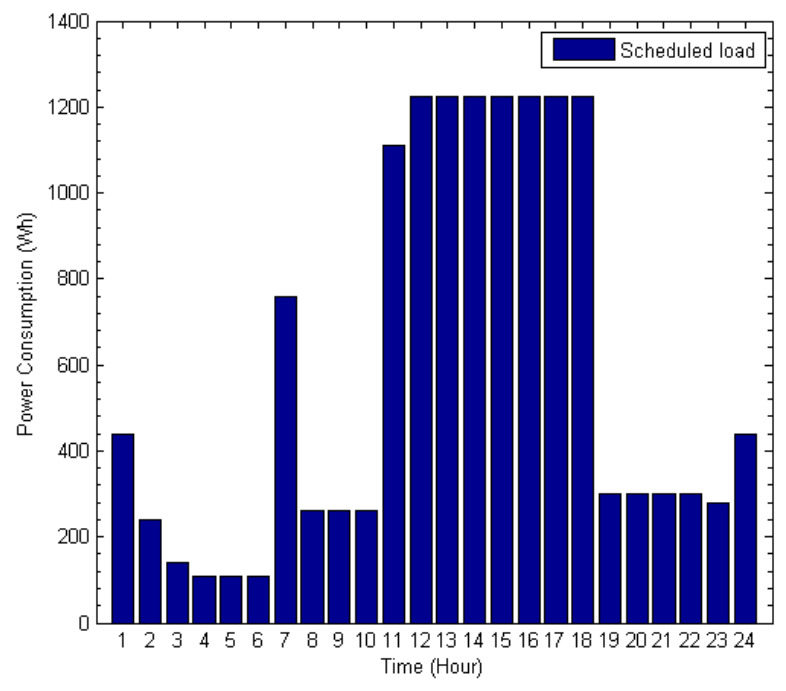

Figure 3. Scheduled hourly power consumption

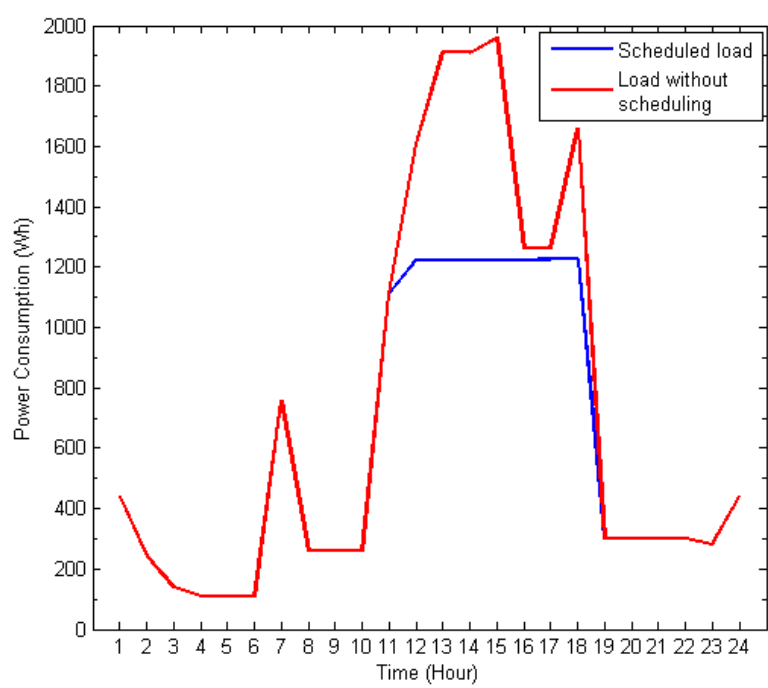

Figure 4. Compare scheduled and without scheduling 


\section{Conclusions}

In this paper, we propose power consumption scheduling for shaving peak load at home area using linear programming technique. This proposed method of saving the energy into residential ESS brought from PHEV via V2G and optimizing the saved energy through linear programming. Through proposed method, we can get the effect of cutting down $38 \%$ on the hourly peak load.

As a result, proposed method is expected that it will be a great help in preventing rolling blackouts and blackouts.

\section{ACKNOWLEDGMENT}

This work was partly supported by the IT R\&D program of MKE/KEIT [10039160, Research on Core Technologies for Self-Management of Energy Consumption in Wired and Wireless Networks]

And Following are results of a study on the "Leaders INdustry-university Cooperation" Project, supported by the Ministry of Education

* Corresponding Author: Seong Gon Choi (sgchoi@cbnu.ac.kr)

\section{REFERENCES}

[1] http://www.kepco.co.kr

[2] F. Li and et al., "Smart transmission grid: Vision and framework," IEEE transactions on Smart Grid, vol. 1, no. 2, pp. 168-177, Sep.2010.

[3] Gireldez, J. and Roche, R. and Suryanarayanan, S. and Zimmerle, D. "A Linear Programming Methodology to Quantify the Impact of PHEVs with V2G Capabilities on Distribution Systems," Green Technologies Conference, 2013 IEEE, pp. 8-15, Apr. 2013.

[4] Ziming Zhu and Jie Tang and Lambotharan, S. and Woon Hau Chin and Zhong Fan, "An integer linear programming based optimization for home demand-side management in smart grid," Innovative Smart Grid Technologies (ISGT), 2012 IEEE PES, pp. 1-5, Jan. 2012.

[5] Dan Wang and Fang-Zheng Peng, "Smart Gateway Grid: A DG-Based Residential Electric Power Supply System," Smart Grid, IEEE Transactions on, vol. 3, no. 4, pp. 2232-2239, Dec. 2012

[6] Kisacikoglu, M.C. and Ozpineci, B. and Tolbert, L.M., "Examination of a PHEV bidirectional charger system for $\mathrm{V} 2 \mathrm{G}$ reactive power compensation," Applied Power Electronics Conference and Exposition (APEC), 2010 Twenty-Fifth Annual IEEE, pp. 458-465, Feb. 2010.

[7] http://en.wikipedia.org/wiki/Vehicle-to-grid

[8] K. Morrow, D. Karner, and J. Francfort, "Plug-in hybrid electric vehicle charging infrastructure review," US Department of Energy Vehicle Technologies Program, Tech. Rep., 2008.

[9] Willett Kempton and Jasna Tomić, "Vehicle-to-grid power fundamentals: Calculating capacity and net revenue," Journal of Power Sources, vol. 144, no. 1, pp. 268-279, Jun. 2005.

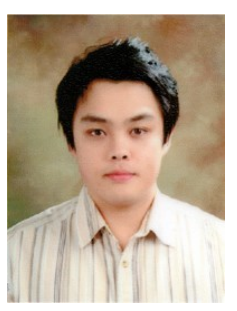

Jae Yong Lee received B.S. degree in College of Electrical \& Computer Engineering, Chungbuk National University, Korea in 2013. He is currently a M.S. candidate in College of Electrical \& Computer Engineering, Chungbuk National University. His research interests include V2G, ESS, and Smart Grid.

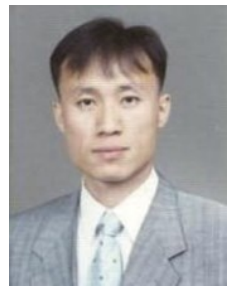

Seong Gon Choi received B.S. degree in Electronics Engineering from Kyeongbuk National University in 1990, and M.S. and Ph.D. degree from Korea Advanced Institute of Science and Technology (KAIST) in 1999 and 2004, respectively. Currently, he is an associate professor in College of Electrical \& Computer Engineering, Chungbuk National University. His research interests include mobile communication, green networks, smart grid (future power grid), high-speed network architectures and protocols. 